\title{
Systematic Reviews and Librarians: A Primer for Managers
}

\author{
Genevieve C. Gore \\ Liaison Librarian \\ Life Sciences Library \\ McGill University \\ genevieve.gore@mcgill.ca \\ Julie Jones \\ GIS \& Map Librarian / Liaison Librarian for Geography \\ Simon Fraser University Library \\ julie_jones@sfu.ca
}

\section{Abstract}

Systematic reviews - and research syntheses in general-are increasing as a form of research. As a result, academic librarians from across disciplines are seeing a growth in the number of requests for library resources and services to support the development and publication of systematic reviews. In some cases, librarian involvement with systematic reviews takes the form of co-authorship. This article will arm library decision-makers with an overview of systematic reviews and details of how they differ from traditional literature reviews.

Systematic reviews provide exciting opportunities for libraries such as potential income, increased use of library services, research output, and alignment with the new roles of academic libraries; however, they also raise issues that managers, administrators, and leaders need to understand and address if librarians are to succeed in these evolving partnerships with their research communities. Significant issues raised include: training and mentoring, time commitment, tenure and promotion, workload, student and research support, and funding.

\section{Keywords}

systematic reviews, research syntheses, library management, librarian as research partner, research services, expert searching

\section{Introduction}

Systematic reviews are proliferating as a form of research publication across a wide range of disciplines as the demand for evidence-based approaches grows (Bastian, Glasziou, and Chalmers 5; Fehrmann and Thomas 16-17). The discipline of health sciences is often assumed to be the main producer of this type of research but 
examples from other disciplines increasingly abound and are now found in fields such as management (Hohenstein et al. 90-117), social work (McFadden, Campbell, and Taylor 1-18), urban planning (Bowler et al. 147-55), education (Busch et al. 245-74), housing (Sautkina, Bond, and Kearns 748-82), and environmental science (Savilaakso et al. 1-21). Systematic reviews are, in simple terms, studies of studies, and they form a sub-category of research syntheses (Chalmers, Hedges, and Cooper 16). They aim to locate all studies on a particular topic, intervention, or research question so that evidence can be synthesized and analyzed. As such, they require systematically and comprehensively searching the literature and then documenting the search strategy for replicability and to allow the synthesis to be updated. This aspect of systematic reviews has been recognized as particularly challenging by the "bible" of systematic reviews, the Cochrane Handbook for Systematic Reviews of Interventions 4.2.6: "[C]onducting a comprehensive, objective and reproducible search for studies can be the most timeconsuming and challenging task in preparing a systematic review" (Higgins and Green 76). To address this requirement, many methodological guides to research synthesis are now specifically listing librarian or information specialist involvement in the search process (see Table 1). As a result, librarians are being called upon to provide support as instructors, expert searchers, co-authors, and even in some cases as dedicated systematic review librarians (Cooper and Crum 71-71; Karasmanis and Murphy 4; Monroe-Gulick, O'Brien, and White 385-86). Furthermore, this phenomenon is on the increase, as evidenced by Crum and Cooper's 2013 study in which 525 medical librarians and library directors $(46 \%$ of whom were in an academic health sciences library) were surveyed with regard to what they considered emerging roles: The top response from library directors in academic settings was "support for systematic reviews" (86\% reported this as an added or planned role in their libraries), while $71 \%$ of medical librarians in academic settings reported this as an added or planned role (280-281).

Given these developments, senior administrators and library managers must fully understand the steps involved in a systematic review or research synthesis, and the issues and opportunities that these methodologies raise in the use of library services and resources. Library leaders need to understand how the growing popularity of systematic reviews is impacting librarians so that services and resources can be planned and delivered accordingly. The objectives of this paper are: To define what a systematic review or research synthesis is, to identify librarian involvement in the process, and to describe the value of this involvement and the issues it raises in libraries. This paper may be used to inform decisions connected to strategic planning and succession planning, as well as professional development and continuing education for librarians. 
Table 1

\section{Examples of research synthesis*}

Campbell (systematic) reviews
Reference to expert searching, involvement of information specialist, or similar concept
Cochrane (systematic) reviews
The Campbell Collaboration states that "[r]elevant methodological expertise includes: information/library science (searching and text retrieval)"
"If a [Cochrane Review Group] is currently without a Trials Search Co-ordinator authors should seek the guidance of a local healthcare librarian or information specialist, where possible one with experience of conducting searches for systematic reviews." (Lefebvre, Manheimer, and Glanville 6.1.1.1)
In "Finding Evidence for Comparing Medical Interventions" published by the Agency for Healthcare Research and Quality (AHRQ, US), Relevo and Balshem state that "[a] librarian or other expert searcher should be involved in the development of the search"
Knowledge syntheses
"2.2 Expertise, Experience and Resources

[...]

It is strongly recommended that each team includes an expert in the content area(s) covered by the synthesis, an expert in synthesis methods and an information scientist or librarian." (Canadian Institutes of Health Research, "Knowledge Synthesis")

\begin{tabular}{|c|c|}
\hline $\begin{array}{l}\text { (Systematic) Mixed } \\
\text { studies reviews }\end{array}$ & $\begin{array}{l}\text { "[l]nvolve specialized librarians (e.g., steps } b-c) \text { " (Pluye } \\
\text { and Hong 36) }\end{array}$ \\
\hline $\begin{array}{l}\text { Network meta- } \\
\text { analyses (NMAs) }\end{array}$ & $\begin{array}{l}\text { "Conclusion: Literature searches in NMAs could be } \\
\text { improved by searching more sources, and by involving a } \\
\text { librarian or information specialist." (Li et al. 1001) }\end{array}$ \\
\hline $\begin{array}{l}\text { Overviews of reviews } \\
\text { (also called umbrella } \\
\text { reviews, meta-reviews) }\end{array}$ & $\begin{array}{l}\text { "Information specialist: May be required when complex } \\
\text { searches of the Cochrane Library are needed" (Thomson et al. } \\
\text { 201) }\end{array}$ \\
\hline $\begin{array}{l}\text { Rapid evidence } \\
\text { assessments (REAs) }\end{array}$ & $\begin{array}{l}\text { In the United Kingdom, the Civil Service guidance on REAs } \\
\text { states, with regard to literature searching, that "[t]his stage of } \\
\text { the project will benefit from the help of a librarian or } \\
\text { information specialist because they can advise on devising } \\
\text { a search strategy." }\end{array}$ \\
\hline & "To mitigate the risk of the REA being affected by publication \\
\hline
\end{tabular}


bias, it is critical to develop a sound search strategy.

Experienced information professionals are important in any review activity, but may be particularly valuable in helping to develop highly efficient search strategies." (Thomas, Newman, and Oliver 18)

\begin{tabular}{|c|c|}
\hline Rapid reviews & $\begin{array}{l}\text { "An Information Specialist at [the Canadian Agency for } \\
\text { Drugs and Technology in Health] works with the research } \\
\text { team to develop a search strategy in accordance with } \\
\text { information gathered during the refinement } \\
\text { phase." (Khangura et al. 22) } \\
\text { "The search strategy is developed and conducted by an } \\
\text { information specialist working in consultation with the } \\
\text { researcher and requestor." (Canadian Centre on Substance } \\
\text { Abuse 3) }\end{array}$ \\
\hline \multirow[t]{3}{*}{$\begin{array}{l}\text { Scoping } \\
\text { studies/reviews }\end{array}$} & $\begin{array}{l}\text { "Researchers may not have the skills necessary for designing } \\
\text { and executing sensitive search strategies that qualified } \\
\text { librarians have" (Arksey and O'Malley 24) }\end{array}$ \\
\hline & $\begin{array}{l}\text { Need to determine whether "technical searching skills are } \\
\text { available to assist with the searches" (Arksey and O'Malley 24) }\end{array}$ \\
\hline & $\begin{array}{l}\text { "[W]e recommend that a scoping study team be assembled } \\
\text { whose members provide the methodological and context } \\
\text { expertise needed for decisions regarding breadth and } \\
\text { comprehensiveness." (Levac, Colquhoun, and O'Brien 5) }\end{array}$ \\
\hline
\end{tabular}

Systematic (literature) reviews
In Finding What Works in Health Care, the Institute of Medicine includes the following standard:

"Standard 3.1 Conduct a comprehensive systematic search for evidence

Required elements:

3.1.1 Work with a librarian or other information specialist trained in performing systematic reviews (SRs) to plan the search strategy" (Committee on Standards for Systematic Reviews of Comparative Effectiveness Research 84) The Centre for Reviews and Dissemination states the following: "A review team should be established to manage and conduct the review. The membership should provide a range of skills, including expertise in systematic review methods, information retrieval, the relevant clinical/topic area, statistics, health economics and/or qualitative research methods where appropriate."

* This table is not an exhaustive list of research syntheses 


\section{Defining the Systematic Review}

What is a systematic review? According to the Health Technology Assessment (HTA) Glossary, it is "a synthesis that collates all empirical evidence fitting pre-specified eligibility criteria in order to answer a specific research question." A systematic review is a study of studies and involves a rigorous and transparent methodology to identify as many studies as possible on a specific research question.

Next, studies are screened for inclusion or exclusion based on predefined criteria. All included studies are critically appraised and synthesized in qualitative or quantitative form using a meta-analytic approach when appropriate. Systematic reviews are not the same as narrative or traditional literature reviews (which often synthesize only a small amount of selected studies and are not explicit about how those studies were located or selected), even if the principles of systematic searching can be applied to any type of review: "[T] he systematic review is designed to remove bias by employing a scientific methodology to comprehensively identify, critically appraise, and synthesize all of the potentially relevant literature on a given topic" (Harris 82).

\section{How Is this Different from Traditional Literature Searching?}

Systematic reviews take the traditional role of librarians as searchers into the more advanced role of expert searcher (Dudden and Protzko 313; Fyfe and Dennett 12-13; Harris 84-85; Karasmanis and Murphy 4; Lasserre 4; McGowan and Sampson 74-75). Systematic reviews and other forms of research synthesis use a methodology which includes a transparent and rigorously documented approach to the retrieval of relevant studies, ideally described in a protocol before the initiation of the study. This approach extends to the search strategy; to the decisions used to include or exclude studies during the record screening process (i.e., determination of eligibility) and full-text reading; to the critical appraisal process; and to the culminating analysis, or synthesis, of the final list of included studies (Liberati et al. 3). Researchers often screen thousands of records when conducting a systematic review because searches are designed to be sensitive (i.e., have high recall) at the cost of precision (McGowan and Sampson 76). The goal is to retrieve as many of the relevant studies as possible using a combination of subject headings (if available), keywords (if available), and text words for each concept. Inadvertently missing certain studies or failing to retrieve all relevant studies could lead to a biased study (Golder, Loke, and McIntosh 440; Harris 82; McGowan and Sampson 79; McKibbon 207; Swinkels, Briddon, and Hall 249-50). Librarians are key partners in this critical step to avoid a flawed search.

Librarian involvement may or may not include the following: helping refine the research question (a process which often includes extensive preliminary searches); setting inclusion and exclusion criteria; selecting which databases and grey literature sources will be searched in the study; developing the search strategy for the primary database; translating the search strategy from the primary database search to other databases specified in the protocol; exporting bibliographic records from multiple databases to citation software (e.g., EndNote, Zotero, RefWorks); removing duplicate records from 
the citation library (a process which is time-intensive despite available functionality in citation software); hand searching journals and the reference lists of articles; conducting citation searching for key articles; searching the grey literature to include unpublished results; writing the methods section of the paper (often including detailed information about database scope and functionality) and documenting search strategies for appendices; reviewing the final manuscript; and updating the searches at a later point in time (Harris 86; Rethlefsen, Murad, and Livingston 1000). Librarians are also becoming involved in other steps such as screening records, critical appraisal, and data extraction (Beverley, Booth, and Bath 70; Dudden and Protzko 308; Rethlefsen, Murad, and Livingston 1000).

\section{What Are the Positive Implications for Libraries?}

\section{Research Output}

Librarian involvement in systematic reviews can range from providing basic guidance on developing a search strategy to the role of a co-author who makes intellectual contributions to the study. The level of involvement in the research process should guide consideration for co-authorship and librarians should make this clear from their initial meetings with researchers, if appropriate. For example, the International Committee of Medical Journal Editors (ICMJE) recommends that authorship be based on four criteria: substantial contribution to the work, drafting and revising of the manuscript, final approval of the version for publication, and accountability for the research itself (sec. 2). Librarians involved as co-authors in systematic reviews are likely to assume responsibility for the search strategy-which counts as a substantial contribution (McGowan and Sampson 79) - and are natural candidates to write the methods section for the manuscript. As co-authors, they are also given the opportunity to approve the final manuscript and thereby become accountable for the research. Even if librarians, either by their own choice or for other reasons, are not included as coauthors, acknowledgement is often given for their contribution, which librarians should be at liberty to accept or reject.

Ideally, library policies or guidelines should help librarians make these points clear to potential collaborators. Some libraries are in fact developing policies or guidelines regarding what level of service librarians are able to provide in the process (Cruse and Protzko 329-30; Hardi and Fowler 417-18; Nauche and Landry slides 9-13). In academic settings, co-authorship may be of particular importance to tenure-track librarians who have the same motivation to publish as other academics (i.e., career advancement) (Freedman 547-48; Janke and Rush 120; Lorenzetti and Rutherford 282; Monroe-Gulick, O'Brien, and White 386). To clarify the potential role of librarians as coauthors, some libraries are explicitly stating what form of involvement constitutes the basis for co-authorship. In two extreme examples, the Health Sciences Library at the Northern Ontario School of Medicine and the Medical Library at the Weill Cornell Medical College bluntly state on their websites that "[I]ibrarians are co-authors on systematic review collaborations." 
Co-authorship may also be an issue in affiliated teaching hospitals where research activities are frequently conducted (Heimlich 28; Nauche and Landry slide 12). The McGill University Health Centre (MUHC) Libraries include a Memorandum of Understanding on their website which makes explicit what level of librarian involvement constitutes grounds for co-authorship (Nauche and Landry slide 12).

In addition to collaborating as co-authors, librarians may be called upon to participate in grant applications involving research syntheses due to their role as expert searchers. As quoted in Table 1, the "Tips for Success" web page on knowledge synthesis grants offered by the Canadian Institutes of Health Research (CIHR) includes a strong recommendation to include an information scientist or librarian on the team.

\section{Potential Income}

Some libraries and librarians charge consulting fees for systematic, comprehensive searches (Cruse and Protzko 329-30; Dudden and Protzko 313; Karasmanis and Murphy 5; Nauche and Landry slide 5). For example, as of February 2015, the W. K. Kellogg Health Sciences Library at Dalhousie University reserved the right to charge $\$ 50$ CDN per hour for a comprehensive search for affiliates of the University and \$75 CDN per hour for non-affiliates.

\section{Increased Use and Evolution of Library Services}

Librarian involvement in systematic reviews is arguably leading to an increase in the visibility of librarians' skills as expert searchers and as research collaborators. Even if a librarian isn't directly involved in a systematic review, many researchers-especially those who are new to systematic reviews - want to have at least some librarian assistance, usually via individual consultations. These consultations can involve: an explication of the steps and methodology involved in a systematic review; assistance determining the research question, selection criteria, and running scoping searches; instruction with regard to the citation management software used for the systematic review; explication of database scope and functionalities; assistance with and advice with regard to database selection; search string construction and troubleshooting; and assistance with grey literature searching, which often includes hand searching as well as advanced web searching (for an example of a study that uses systematic approaches for searching for policy literature on the open web, please see Austin et al. 627).

Some libraries are responding with web guides, tutorials, and workshops that researchers can be initially directed to so that time-intensive consultations can be as sophisticated as possible and avoided if unnecessary. This complex support that librarians are offering may be best described as "research support services" and it represents an evolution of academic librarianship. Librarians' roles are evolving, and librarians are increasingly advising researchers on methodology. 


\section{Alignment with New Roles and Demonstration of the Value of Academic Libraries}

Another way to view these realities is as an excellent example of librarians moving into the new types of roles outlined in the 2013 ARL report by Jaguszewski and Williams entitled New Roles for New Times: Transforming Liaison Roles in Research Libraries. This report highlights evolving research methods as one of the forces transforming higher education and calls for an "engagement model" of librarianship, stating, "An engaged liaison seeks to enhance scholar productivity, to empower learners, and to participate in the entire lifecycle of the research, teaching, and learning process" (4). The increase in partnerships with systematic review teams outside the library is an example of the engagement model, and the increasing popularity of systematic reviews is an example of an evolving research method. Furthermore, in this age of needing to articulate the value of academic libraries-through assessment, alignment with institutional goals, alignment with learning objectives and accreditation-librarian involvement in systematic reviews is quantifiable evidence of the impact of academic libraries on research. For these reasons, supporting systematic reviews should be embraced as an opportunity for academic libraries to evolve their services and make a stronger impact on the research landscape.

\section{What Are the Significant Issues Raised by Increased Librarian Involvement in Systematic Searching?}

\section{Training and Mentoring}

Providing support for systematic reviews requires training and mentoring for librarians (Fyfe and Dennett 13-14; Lefebvre et al. 5). Without this support, librarians may find they lack the skills and/or the confidence to be involved in systematic reviews and may be unable to respond to their communities' needs in this area. Training sessions not offered locally require travel funds and adjustment of regular duties. Mentoring and training are especially important for librarians who are the solo providers of systematic review support for their institutions. The same can be stated with regard to librarians in subject areas where systematic reviews are an emerging approach and are therefore new methodological territory for both the discipline's researchers and the librarian. Anticipating the future directions in research within a discipline becomes more important than ever when considered in this context.

\section{Time}

Systematic searches are time-consuming and labour-intensive by nature, and lack of time is a barrier to taking on new roles in the support of systematic reviews (Crum and Cooper 284). A comprehensive search can take hours or even days to develop (McGowan and Sampson 76; Karasmanis and Murphy 6; Nauche and Landry slide 28), as shown in a study by Saleh, Ratajeski, and Bertolet which reported a median time of 471 minutes and a mean time of 1,457 minutes for systematic review searches, including searches of grey literature sources (36). In addition to the time spent searching, systematic reviews often involve multiple meetings and exchanges with other 
members of the research team. This is especially true at the beginning of a study, as decisions made at this stage commit researchers to a course of action that cannot be changed once set in motion and are therefore tremendously important and must involve all collaborators. Systematic reviews involve a significant time commitment for librarians and they must juggle the inherent workload of systematic reviews with preexisting schedules and activities. If librarians' supervisors do not understand the time involved in their undertaking, they risk not being well positioned to advocate for additional staffing needs, for example. Supervisors may also be unable to fairly evaluate and credit librarians for the amount of work involved in such endeavours.

\section{Value in Tenure Decisions}

Depending on the institutional culture, it may be unclear how the value of co-authorship on systematic reviews can count toward tenure. In addition, some disciplines will not be as familiar with systematic review methodology, and recognition of value may therefore vary between disciplines as well as institutions (Chalmers, Hedges, and Cooper 21-25; Institute for Natural Resources 3). Finally, for librarians as well as their supervisors, it may be up for debate whether collaboration in systematic reviews should count as part of librarians' core responsibilities or as scholarly activity.

\section{Who Pays?}

A potential issue regarding consulting fees is whether librarians are able to charge them given the conditions of granting agencies. For example, the Canadian Institutes of Health Research specifically state for knowledge synthesis grants that non-eligible expenses include "[a]ny part of the salary, or consulting fee, to the grantee or to other persons whose status would make them eligible to apply for grants from the Agency" ("Grants and Awards Guide" 60). Academic librarians may be considered eligible to apply for such grants, thus making their consulting fees non-eligible for grant coverage. In addition, certain grants place significant emphasis on the in-kind contributions of collaborators, including librarians, and require a letter that details contributions as well as an estimated dollar amount for the contributions. ArcticNet (a Network of Centres of Excellence of Canada) proposals are an example of this. Given these realities, libraries may need to explore more complex partnering agreements with campus researchers when grant funding is involved-for example, should a portion of grant money be directed to the library that will make the grant-supported study possible, and if so, how?

\section{Extent of Librarian Involvement}

The parameters of librarian involvement in systematic reviews and other forms of research synthesis also need to be defined because the work may involve unanticipated tasks that naturally spill over from other steps of the process, and there are many grey areas when it comes to the division of labour. Librarians, after having finalized the search strategies, may or may not do the actual exporting of records to citation management software; may or may not remove duplicate records; may or may not be involved in further steps such as screening records, critical appraisal, or data extraction 
as previously mentioned (Beverley, Booth, and Bath 70; Dudden and Protzko 308; Rethlefsen, Murad, and Livingston 1000). Other involvement includes helping researchers find the full-text of articles being considered for final inclusion in the analysis, a process which can be time-consuming and which, regardless of librarian involvement, may result in heavy use of Interlibrary Loan-another issue that administrators and managers should keep in mind (Arksey and O'Malley 24; McGowan and Sampson 78). Finally, librarians may be approached by researchers who do not understand the work or steps involved in conducting a systematic review and may therefore find themselves in the role of providing an overview of the systematic review process and how it differs from "a review of the literature, done systematically" (Heimlich 27). For example, some researchers may not realize that systematic reviews involve at least two reviewers screening records, performing critical appraisal, and extracting data as a mechanism to minimize individual bias. Librarians may find themselves explaining what's really involved when a researcher first begins exploring how to conduct a systematic review. Librarians' expertise is so entwined with research synthesis methodologies that they may find themselves occupying a role that resembles that of a sort of "methodology guidance counsellor" when helping researchers determine if they do, in fact, want to conduct a systematic review.

\section{Supporting Students}

Another major issue faced by librarians is how much assistance to provide to students with their systematic review searches, assignments, and possible publications. Parallel to and in conjunction with the increase in the incidence of systematic reviews being produced in the published literature, there has been a steady increase in the number of systematic reviews completed per year as part of or as students' graduate theses or dissertations (Cobus-Kuo, Gore, and Kloda slide 19). Different institutions likely have different student requirements for completing courses and degrees, but manuscriptbased graduate theses and dissertations are permitted in certain disciplines, as determined by a Google search across the websites of U15 Canadian research universities. Interestingly, it may be acceptable to have co-authors on such manuscripts (Gross, Alhusen, and Jennings 431-32). Even if librarians take a more restricted role as trainers in searching, they may struggle with the time-consuming task of helping students develop their searching skills given the number of students requiring assistance. Other examples of workload issues are librarians offering or supporting courses specifically on the topic of conducting systematic reviews or other forms of knowledge synthesis. Such courses may involve a significant time commitment from subject librarians. For example, professors at one of our institutions offer courses in which students are expected to complete a systematic review in one term. Despite librarians providing in-class sessions on systematic searching, some students still require very high levels of support from the library on an individual basis following instruction. Furthermore, it has been our experience that faculty understand and value the expertise that librarians possess in this area and often encourage-and sometimes even requirestudents to obtain one-on-one assistance with a librarian or to have a librarian sign off on students' searches. 


\section{Conclusion}

Librarians have skills and expertise that make them valuable research partners in the development and publication of systematic reviews and other forms of research synthesis. This is leading to higher visibility and an increased demand for librarians' services and the resources they manage and promote. The increasing number of systematic reviews and other research syntheses being performed and the increased demand for librarian involvement will continue to significantly affect staffing, services, and resources. This current method of information dissemination and retrieval means that administrators and managers may be faced with important choices and decisions regarding how best to not only support this demand, but also to recognize librarian involvement, and anticipate the opportunities and challenges presented by this growing research area.

\section{Works Cited}

ArcticNet. "Full Proposal Application Form -- Phase 4 (2015-2018)." ArcticNet, n.d. Web. 1 Mar. 2015.

Arksey, Hilary, and Lisa O'Malley. "Scoping Studies: Towards a Methodological Framework." International Journal of Social Research Methodology 8.1 (2005): 19-32. Web. 1 Mar. 2015.

Austin, Stephanie E., et al. "Public Health Adaptation to Climate Change in Canadian Jurisdictions." International Journal of Environmental Research and Public Health 12.1 (2015): 623-51. Web. 1 Mar. 2015.

Bastian, Hilda, Paul Glasziou, and lain Chalmers. "Seventy-Five Trials and Eleven Systematic Reviews a Day: How Will We Ever Keep Up?" PLoS Medicine 7.9 (2010): e1000326. Web. 1 Mar. 2015.

Beverley, C. A., A. Booth, and P. A. Bath. "The Role of the Information Specialist in the Systematic Review Process: A Health Information Case Study." Health Information and Libraries Journal 20.2 (2003): 65-74. Web. 1 Mar. 2015.

Bowler, Diana E., et al. "Urban Greening to Cool Towns and Cities: A Systematic Review of the Empirical Evidence." Landscape and Urban Planning 97.3 (2010): 147-55. Web. 1 Mar. 2015.

Busch, Vincent, et al. "The Effects of Adolescent Health-Related Behavior on Academic Performance: a Systematic Review of the Longitudinal Evidence." Review of Educational Research. 84.2 (2014): 245-74. Web. 1 Mar. 2015.

Campbell Collaboration. "Producing a Review." Campbell Collaboration, n.d. Web. 1 Mar. 2015. 
Canadian Centre on Substance Abuse. "CCSA Rapid Review Methodology." Canadian Centre on Substance Abuse, Nov. 2014. Web. 4 May 2015.

Canadian Institutes for Health Research. "Grants and Awards Guide." Canadian Institutes of Health Research, 1 Apr. 2013. Web. 1 Mar. 2015.

---. "Knowledge Synthesis - Tips for Success." Canadian Institutes of Health Research, 7 Jun. 2013. Web. 1 Mar. 2015.

Centre for Reviews and Dissemination. Systematic Reviews: CRD's Guidance for Undertaking Reviews in Health Care. York: Centre for Reviews and Dissemination, 2009. Web. 1 Mar 2015.

Chalmers, Iain, Larry V. Hedges, and Harris Cooper. "A Brief History of Research Synthesis." Evaluation and the Health Professions 25.1 (2002): 12-37. Web. 1 Mar. 2015.

Civil Service. "How to Do a REA." UK Civil Service, n.d. Web. 4 May 2015.

Cobus-Kuo, Laura, Genevieve Gore, and Lorie Kloda. "Research Syntheses in Graduate Research: A Scoping Review." Canadian Health Libraries Association Annual Conference. Montreal, Canada: Canadian Health Libraries Association. 18 Jun. 2014. Web. 1 Mar. 2015.

Committee on Standards for Systematic Reviews of Comparative Effectiveness Research. Finding What Works in Health Care: Standards for Systematic Reviews. Ed. Eden, Jill, Levit, Laura, Berg, Alfred, and Sally Morton. Washington, DC: Institute of Medicine of the National Academies, 2011. Web. 28 Feb. 2015.

Cooper, I. Diane, and Janet A. Crum. "New Activities and Changing Roles of Health Sciences Librarians: A Systematic Review, 1990-2012." Journal of the Medical Library Association 101.4 (2013): 268-77. Web. 1 Mar. 2015.

Crum, Janet A., and I. Diane Cooper. "Emerging Roles for Biomedical Librarians: A Survey of Current Practice, Challenges, and Changes." Journal of the Medical Library Association 101.4 (2013): 278-86. Web. 1 Mar. 2015.

Cruse, Peggy, and Shandra Protzko. "Librarian Contributions to Clinical Practice Guidelines." Medical Reference Services Quarterly 33.3 (2014): 327-34. Web. 1 Mar. 2015.

Dudden, Rosalind F., and Shandra L. Protzko. "The Systematic Review Team: Contributions of the Health Sciences Librarian." Medical Reference Services Quarterly 30.3 (2011): 301-15. Web. 1 Mar. 2015. 
Fehrmann, Paul, and Joelle Thomas. "Comprehensive Computer Searches and Reporting in Systematic Reviews." Research Synthesis Methods 2.1 (2011): 1532. Web. 1 Mar. 2015.

Freedman, Shin. "Faculty Status, Tenure, and Professional Identity: A Pilot Study of Academic Librarians in New England." Portal 14.4 (2014): 533-65. Web. 1 Mar. 2015.

Fyfe, Trina, and Liz Dennett. "Building Capacity in Systematic Review Searching: A Pilot Program Using Virtual Mentoring." Journal of the Canadian Health Libraries Association 33.1 (2012): 12-16. Web. 1 Mar. 2015.

Golder, Su, Yoon Loke, and Heather M. McIntosh. "Poor Reporting and Inadequate Searches Were Apparent in Systematic Reviews of Adverse Effects." Journal of Clinical Epidemiology 61.5 (2008): 440-48. Web. 1 Mar. 2015.

Gross, Deborah, Jeanne Alhusen, and Bonnie Mowinski Jennings. "Authorship Ethics with the Dissertation Manuscript Option." Research in Nursing and Health 35.5 (2012): 431-34. Web. 1 Mar. 2015.

Hardi, Angela C., and Susan A. Fowler. "Evidence-Based Medicine and Systematic Review Services at Becker Medical Library." Missouri Medicine 111.5 (2014): 416-18. Web. 1 Mar. 2015.

Harris, Martha R. "The Librarian's Roles in the Systematic Review Process: A Case Study." Journal of the Medical Library Association 93.1 (2005): 81-87. Web. 1 Mar. 2015.

Heimlich, S. Layla. "New and Emerging Roles for Medical Librarians." Journal of Hospital Librarianship 14.1 (2014): 24-32. Web. 1 Mar. 2015.

Higgins, Julian P. T., and Sally Green, eds. "Locating and Selecting Studies." Cochrane Handbook for Systematic Reviews of Interventions 4.2.6. Eds. Higgins, Julian P. T., and Sally Green. Sept. 2006. Web. 5 May 2015.

Hohenstein, Nils-Ole, et al. "Research on the Phenomenon of Supply Chain Resilience: A Systematic Review and Paths for Further Investigation." International Journal of Physical Distribution \& Logistics Management 45.1/2 (2015): 90-117. Web. 1 Mar. 2015.

"HTA Glossary." HTAGlossary.net. Institut National d'Excellence en Santé et en Services Sociaux (INESSS), n.d. Web. 1 Mar. 2015.

Institute for Natural Resources. "Systematic Review Pilot Project: Final Report." ScholarsArchive@OSU, Feb. 2008. Web. 28 Feb. 2015. 
International Committee of Medical Journal Editors. "Defining the Role of Authors and Collaborators." N.d. Web. 4 May 2015.

Jaguszewski, Janice, and Karen Williams. "New Roles for New Times: Transforming Liaison Roles in Research Libraries." Washington, DC: Association of Research Libraries, 2013. Web. 1 Mar. 2015.

Janke, Robert, and Kathy L. Rush. "The Academic Librarian as Co-Investigator on an Interprofessional Primary Research Team: A Case Study." Health Information \& Libraries Journal 31.2 (2014): 116-22. Web. 1 Mar. 2015.

Karasmanis, Sharon, and Fiona Murphy. "Emerging Roles and Collaborations in Research Support for Academic Health Librarians." Australian Library and Information Association National 2014 Conference. Melbourne, Australia: Australian Library and Information Association, 18 Sept. 2014. Web. 1 Mar. 2015.

Khangura, Sara, et al. "Rapid Review: An Emerging Approach to Evidence Synthesis in Health Technology Assessment." International Journal of Technology Assessment in Health Care 30.1 (2014): 20-27. Web. 4 May 2015.

Lasserre, Kaye. "Expert Searching in Health Librarianship: A Literature Review to Identify International Issues and Australian Concerns." Health Information and Libraries Journal 29.1 (2012): 3-15. Web. 1 Mar. 2015.

Lefebvre, Carol, et al. "Methodological Developments in Searching for Studies for Systematic Reviews: Past, Present and Future?" Systematic Reviews 2 (2013). Web. 1 Mar. 2015.

Lefebvre, Carol, Manheimer, Eric, and Julie Glanville. "Searching for Studies." Cochrane Handbook for Systematic Reviews of Interventions Version 5.1.0. Ed. Higgins, Julian P. T. and Sally Green. Mar. 2011. Web. 28 Feb. 2015.

Levac, Danielle, Heather Colquhoun, and Kelly K. O'Brien. "Scoping Studies: Advancing the Methodology." Implementation Science 5:69 (2010). Web. 1 Mar. 2015.

Li, Lun, et al. "Network Meta-Analyses Could Be Improved by Searching More Sources and by Involving a Librarian." Journal of Clinical Epidemiology 67.9 (2014): 100107. Web. 1 Mar. 2015.

Liberati, Alessandro, et al. "The Prisma Statement for Reporting Systematic Reviews and Meta-Analyses of Studies That Evaluate Health Care Interventions: Explanation and Elaboration." PLoS Medicine 6.7 (2009): e1000100. Web. 1 Mar. 2015.

Lorenzetti, Diane L., and Gayle Rutherford. "Information Professionals' Participation in Interdisciplinary Research: A Preliminary Study of Factors Affecting Successful 
Collaborations." Health Information \& Libraries Journal (2012): 274-84. Web. 1 Mar. 2015.

McFadden, Paula, Anne Campbell, and Brian Taylor. "Resilience and Burnout in Child Protection Social Work: Individual and Organisational Themes from a Systematic Literature Review." British Journal of Social Work (2014): 1-18. Web. 1 Mar. 2015.

McGowan, Jessie, and Margaret Sampson. "Systematic Reviews Need Systematic Searchers." Journal of the Medical Library Association 93.1 (2005): 74-80. Web. 1 Mar. 2015.

McKibbon, Ann. "Systematic Reviews and Librarians." Library Trends 55.1 (2006): 20215. Web. 1 Mar. 2015.

Monroe-Gulick, Amalia, Megan S. O'Brien, and Glen White. "Librarians as Partners: Moving from Research Supporters to Research Partners." Association of College and Research Libraries Conference, Indianapolis, IN, 10-13 Apr. 2013. Association of College and Research Libraries. Indianapolis: ACRL Conference Proceedings, 2013. Web. 1 Mar. 2015.

Nauche, Bénédicte, and Tara Landry. "Implanter un Service en Support aux Revues Systématiques en Milieu Hospitalier: Le Chemin Parcouru par les Bibliothèques du Centre Universitaire de Santé McGill." Canadian Health Libraries Association Annual Conference. Montreal, Canada: Canadian Health Libraries Association. 18 Jun. 2014. Web. 1 Mar. 2015.

Northern Ontario School of Medicine Health Sciences Library. "Search Assistance." Northern Ontario School of Medicine, n.d. Web. 1 Mar. 2015.

Pluye, Pierre, and Quan Nha Hong. "Combining the Power of Stories and the Power of Numbers: Mixed Methods Research and Mixed Studies Reviews." Annual Review of Public Health 35.1 (2014): 29-45. Web. 1 Mar. 2015.

Relevo, Rose, and Howard Balshem. "Finding Evidence for Comparing Medical Interventions." Methods Guide for Effectiveness and Comparative Effectiveness Reviews. AHRQ Methods for Effective Health Care. Rockville (MD): Agency for Healthcare Research and Quality (US), 5 Jan. 2011. Web. 1 Mar. 2015.

Rethlefsen, Melissa L., M. Hassan Murad, and Edward H. Livingston. "Engaging Medical Librarians to Improve the Quality of Review Articles." JAMA - Journal of the American Medical Association 312.10 (2014): 999-1000. Web. 1 Mar. 2015.

Saleh, Ahlam, Melissa A. Ratajeski, and Marnie Bertolet. "Grey Literature Searching for Health Sciences Systematic Reviews: A Prospective Study of Time Spent and Resources Utilized." Evidence Based Library and Information Practice 9.3 (2014): 28-50. Web. 4 May. 2015. 
Sautkina, Elena, Lyndal Bond, and Ade Kearns. "Mixed Evidence on Mixed Tenure Effects: Findings from a Systematic Review of UK Studies, 1995-2009." Housing Studies 27.6 (2012): 748-82. Web. 1 Mar. 2015.

Savilaakso, Sini, et al. "Systematic Review of Effects on Biodiversity from Oil Palm Production." Environmental Evidence 3.1 (2014): 1-21. Web. 1 Mar. 2015.

Swinkels, Annette, Jason Briddon, and Jane Hall. "Two Physiotherapists, One Librarian and a Systematic Literature Review: Collaboration in Action." Health Information and Libraries Journal 23.4 (2006): 248-56. Web. 1 Mar. 2015.

Thomas, James, Mark Newman, and Sandy Oliver. "Rapid Evidence Assessments of Research to Inform Social Policy: Taking Stock and Moving Forward." Evidence \& Policy: A Journal of Research, Debate and Practice 9.1 (2013): 5-27. Web. 4 May 2015.

Thomson, Denise, et al. "The Evolution of a New Publication Type: Steps and Challenges of Producing Overviews of Reviews." Research Synthesis Methods 1.3-4 (2010): 198-211. Web. 1 Mar. 2015.

W. K. Kellogg Health Sciences Library. "Literature Search Services Policy." Dalhousie University, 2013. Web. 1 Mar. 2015.

Weill Cornell Medical College Medical Library. "Systematic Review Service." Weill Cornell Medical College, n.d. Web. 1 Mar. 2015. 